\title{
FAKTOR-FAKTOR YANG BERHUBUNGAN DENGAN KEPUASAN PASIEN TERHADAP PELAYANAN KEPERAWATAN DI PUSKESMAS RAWAT INAP SE-KABUPATEN KUNINGAN TAHUN 2017
}

\author{
FACTORS CONNECTED WITH PATIENT SATISFACTION TO NURSING \\ SERVICES IN PUBLIC HOSPITAL INTERESTS SE-BRASS DISTRICT IN YEAR \\ 2017
}

\author{
Aria Pranatha ${ }^{1}$, Rany Muliany Sudirman ${ }^{2}$, Nita Novitasari $^{3}$ \\ E-mail: ners.ariap79@gmail.com
}

\begin{abstract}
ABSTRAK
Pendahuluan: Kepuasan pasien merupakan salah satu indikator untuk menilai baik atau buruknya mutu pelayanan keperawatan yang diberikan. Berdasarkan study pendahuluan di dua puskesmas dengan 17 responden mengatakan sebagian besar pasien mengatakan pelayanan baik sehingga pasien merasa puas dan sebagian lainnya mengatakan pelayanan masih harus diperhatikan lagi salah satunya dalam kebersihan toilet. Tujuan: Penelitian ini bertujuan untuk mengetahui faktor-faktor yang berhubungan dengan kepuasan pasien terhadap pelayanan keperawatan di Puskesmas Rawat Inap Se-Kabupaten Kuningan. Metode: Jenis penelitian analitik observasional dengan pendekatan cross sectional. Populasi 714 orang dengan teknik pengambilan sampel accidental sampling sebanyak 56 responden. Pengumpulan data menggunakan kuesioner. Analisa statistik dilakukan secara univariat menggunakan deskriptif frekuensi dan bivariat dengan menggunakan metode chi square. Hasil: Hasil menunjukkan pada variabel bebas yaitu $(62,5 \%)$ perawat baik, $(71,4 \%)$ perawat handal, $(55,4 \%)$ perawat cepat tanggap, $(57,1 \%)$ perawat menjamin informasi, $(62,5 \%)$ perawat empati, dan $(51,8 \%)$ pasien merasa puas. Hasil Analisis chi square pada variabel terikat menunjukan variabel kenyataan $p$-value $=0,001$, variabel kehandalan $p$ value $=0,002$, variable ketanggapan $p$-value $=0,000$, variabel jaminan $p$-value $=0,016$, dan variabel empati $p$-value $=0,000$. Diskusi: terdapat hubungan yang bermakna antara variabel kenyataan, kehandalan, ketanggapan, jaminan \& empati dengan kepuasan pasien. Disarankan pada puskesmas rawat inap yang terkait untuk lebih meningkatkan lagi sarana prasarana dan kualitas pelayanan agar pasien lebih merasa puas.
\end{abstract}

Kata Kunci: Puskesmas, kepuasan pasien, pelayanan keperawatan

\section{ABSTRACT}

Introduction: Patient satisfaction is one of indicator to assess good or bad quality of nursing service given. Based on a preliminary study in two health centers with 17 respondents said most patients said the service was good so that the patient was satisfied and some said the service still had to be considered again one of them in the cleanliness of toilets. Purpose: This study aims to determine the factors related to patient satisfaction with nursing services in Inpatient Health Centers in Kuningan Regency. Method: Type of observational analytic study with cross sectional approach. Population 714 people with sampling technique accidental sampling counted 56 respondents. Data collection using questionnaires. Statistical analysis was done univariat using descriptive frequency and bivariate by using chi square method. Results: The results showed that the independent variables were (62.5\%) good nurses, $(71.4 \%)$ reliable nurses, (55.4\%) nurses responsive, $(57.1 \%)$ nurses guarantee information, (62.5\%) empathy nurses, and (51.8\%) patients feel satisfied. Results Chi square analysis on the dependent variable shows the reality variable $p$-value $=0.001$, $p$-value reliability variable $=0.002$, responsiveness variable $p$-value $=0.000$, guarantee variable $p$-value $=0.016$, and empathy variable $p$-value $=0.000$. Discussion: there is a significant relationship between reality variables, reliability, responsiveness, assurance \& empathy with patient satisfaction. It is recommended that inpatient health centers are related to further improve infrastructure and quality of service so that patients 
Keywords: Puskesmas, patient satisfaction, nursing services

\section{PENDAHULUAN}

Jenis puskesmas ada dua yaitu puskesmas non-perawatan dan puskesmas perawatan. Puskesmas perawatan yaitu puskesmas yang memiliki fasilitas rawat inap kemudian yang diberi tambahan ruangan dan fasilitas untuk menolong pasien gawat darurat, baik berupa tindakan operatif terbatas maupun rawat inap sementara (Effendi, 2009).

Jumlah tenaga perawat merupakan tenaga paling banyak bila dibandingkan dengan tenaga kesehatan yang lainnya, sehingga perannya menjadi penentu dalam pelayanan kesehatan baik di Puskesmas maupun rumah sakit. Selain itu, perawat juga yang berinteraksi selama 24 jam dengan pasien untuk melaksanakan layanan keperawatan.

Dalam Pusat Kesehatan Masyarakat atau Puskesmas terdapat upaya kesehatan masyarakat yaitu setiap kegiatan untuk memelihara dan meningkatkan kesehatan serta mencegah dan menanggulangi timbulnya masalah kesehatan dengan sasaran keluarga, kelompok, dan masyarakat menurut Kementerian Kesehatan RI (2015). Layanan keperawatan adalah suatu upaya untuk membantu individu baik yang sehat maupun sakit, dari lahir sampai meninggal dalam bentuk peningkatan pengetahuan, kemauan dan kemampuan yang dimiliki sehingga individu tersebut dapat melakukan kegiatan sehari-hari secara mandiri dan optimal. Layanan keperawatan memiliki peran penting dalam pembangunan kesehatan guna meningkatkan derajat kesehatan masyarakat. Apabila berbagai masalah kesehatan masyarakat tidak teratasi maka tujuan pembangunan kesehatan akan terhambat menurut Zaidin (2012).
Hasil penelitian yang dilakukan oleh Krisdaryeti dan Sumaryono tentang hubungan mutu pelayanan kesehatan dengan kepuasan pasien di Puskesmas Gandus Palembang pada tahun 2013, terhadap responden yang berjumlah 96 orang dengan hasil 56 responden menyatakan puas dan 40 menyatakan tidak puas. Ketidakpuasan pasien tersebut terdiri dari aspek kebersihan, kemampuan petugas puskesmas dalam menyelesaikan keluhan pasien, keramahan dan kesopanan. Maka dari itu kepuasan pasien sangat penting dalam mengevaluasi atas kualitas layanan dengan mengukur sejauh mana respon pasien setelah menerima jasa. Menurut Pohan (2007) kepuasan pasien adalah suatu tingkat perasaan pasien yang timbul sebagai akibat dari kinerja layanan kesehatan yang diperolehnya setelah pasien membandingkannya dengan apa yang diharapkan.

Berdasarkan Profil Dinas Kesehatan Kabupaten Kuningan pada tahun 2015, Puskesmas rawat inap di Kabupaten Kuningan ada 6 puskesmas dengan jumlah kunjungan di puskesmas rawat inap yaitu 9.048 orang pertahun. Sedangkan Puskesmas non rawat inap yang berjumlah 31 puskesmas dengan jumlah kunjungan pasien 269.110 orang pertahun.

Hasil study pendahuluan yang dilakukan peneliti di Puskesmas Cilimus, dengan cara membagikan lembar pertanyaan tentang kepuasan pasien, terhadap 10 pasien rawat inap, menyatakan baik pada variabel tangible (kenyataan) yaitu 7 responden dan kurang baik pada variabel tangible (kenyataan) yaitu 3 responden, pada variabel reliability (keandalan) yang menyatakan handal yaitu 5 responden dan yang menyatakan tidak handal yaitu 5 
responden, pada variabel responsiveness (tanggung jawab) yang menyatakan tanggap yaitu 4 responden dan yang menyatakan tidak tanggap yaitu 6 responden, pada variabel assurance (jaminan) yang menyatakan terjamin yaitu 7 responden dan yang menyatakan tidak terjamin yaitu 3 responden, pada variabel empathy (empati/peduli) yang menyatakan empati yaitu 6 responden dan yang menyatakan tidak empati 4 responden.

Sedangkan study pendahuluan yang dilakukan di Puskesmas Luragung pada 7 pasien yang sedang dirawat inap, menyatakan baik pada variabel tangible (kenyataan) yaitu 3 dan yang menyatakan kurang baik yaitu 4 responden, pada variabel reliability (keandalan) yang menyatakan handal yaitu 5 responden dan yang menyatakan tidak handal yaitu 2 responden, pada variabel responsiveness (tanggung jawab) yang menyatakan tanggap yaitu 3 responden dan yang menyatakan tidak tanggap yaitu 4 responden, pada variabel assurance (jaminan) yang menyatakan terjamin yaitu 5 responden dan yang menyatakan tidak terjamin yaitu 2 responden, pada variabel empathy (empati/peduli) yang menyatakan empati yaitu 6 responden dan yang menyatakan tidak empati yaitu 1 responden.

Berdasarkan uraian fenomena di atas maka peneliti tertarik untuk mengidentifikasi masalah tersebut sebagai penelitian dengan judul "Faktor Faktor Yang Berhubungan Dengan Kepuasan Pasien Terhadap Pelayanan Keperawatan Rawat Inap di Puskesmas SeKabupaten Kuningan”.

\section{BAHAN DAN METODE}

Penelitian yang digunakan termasuk kedalam penelitian kuantitatif dengan menggunakan jenis penelitian analitik observasional dengan pendekatan cross sectional yang bertujuan untuk melihat apakah ada hubungan atau tidak antara faktor tangible, reliability responsiveness, assurance dan empath dengan kepuasan pasien terhadap pelayanan keperawatan di Puskesmas Rawat Inap Se-Kabupaten Kuningan. Populasi 714 orang dengan teknik pengambilan sampel accidental sampling sebanyak 56 responden. Pengumpulan data menggunakan kuesioner. Analisa statistik dilakukan secara univariat menggunakan deskriptif frekuensi dan bivariat dengan menggunakan metode $c h i$ square.

\section{HASIL}

1. Analisa Univariat

a. Gambaran Faktor Tangible Terhadap Pelayanan Keperawatan Di Puskesmas Rawat Inap SeKabupaten Kuningan Tahun 2017

Tabel 1.

Tangible (Kenyataan) Frekuensi Persentase (\%)

\begin{tabular}{ccc}
\hline Baik & 35 & $62,5 \%$ \\
Kurang Baik & 21 & $37,5 \%$ \\
Total & 56 & $100 \%$
\end{tabular}

Sumber: Data Primer (2017

Berdasarkan tabel 5.1 di atas, dapat dilihat bahwa sebagian besar $(62,5 \%)$ responden menyatakan bahwa faktor tangible (fasilitas puskesmas dan penampilan perawat) baik.

b. Gambaran Faktor Reliability Terhadap Pelayanan Keperawatan 
Di Puskesmas Rawat Inap SeKabupaten Kuningan Tahun 2017

Tabel 2.

\begin{tabular}{ccc}
\hline $\begin{array}{c}\text { Reliability } \\
\text { (kehandalan) }\end{array}$ & Frekuensi & Persentase (\%) \\
\hline Handal & 40 & $71,4 \%$ \\
Tidak Handal & 16 & $28,6 \%$ \\
Total & 56 & $100 \%$ \\
\hline
\end{tabular}

Sumber: Data Primer (2017)

Berdasarkan tabel 2. di atas, dapat dilihat bahwa sebagian besar $(71,4 \%)$ responden menyatakan bahwa dilayani oleh perawat yang handal.

c. Gambaran Faktor Responsiveness Terhadap Pelayanan Keperawatan Di Puskesmas Rawat Inap SeKabupaten Kuningan Tahun 2017

Tabel 3.

\begin{tabular}{ccc}
\hline $\begin{array}{l}\text { Responsiveness } \\
\text { (ketanggapan) }\end{array}$ & Frekuensi & $\begin{array}{c}\text { Persentase } \\
\text { (\%) }\end{array}$ \\
\hline Tanggap & 31 & $55,4 \%$ \\
Tidak Tanggap & 25 & $44,6 \%$ \\
Total & 56 & $100 \%$ \\
\hline
\end{tabular}

Sumber: Data Primer (2017)

Berdasarkan tabel 3. di atas, dapat dilihat bahwa sebagian besar $(55,4 \%)$ responden menyatakan perawat cepat tanggap terhadap keluhan pasien.

d. Gambaran Faktor Assurance Terhadap Pelayanan Keperawatan Di Puskesmas Rawat Inap SeKabupaten Kuningan Tahun 2017

Tabel 4.

\begin{tabular}{ccc}
\hline Assurance (jaminan) & Frekuensi & $\begin{array}{c}\text { Persentase } \\
(\%)\end{array}$ \\
\hline Terjamin & 32 & $57,1 \%$ \\
Tidak Terjamin & 24 & $42,9 \%$ \\
Total & $\mathbf{5 6}$ & $\mathbf{1 0 0 \%}$ \\
\hline
\end{tabular}

Sumber: Data Primer (2017)
Berdasarkan tabel 4. di atas, dapat dilihat bahwa sebagian besar $(57,1 \%)$ responden menyatakan merasa aman dan nyaman terhadap pelayanan yang diberikan oleh perawat.

e. Gambaran Faktor Empathy Terhadap Pelayanan Keperawatan Di Puskesmas Rawat Inap SeKabupaten Kuningan Tahun 2017

Tabel 5.

\begin{tabular}{ccc}
\hline $\begin{array}{c}\text { Empathy } \\
\text { (kepedulian) }\end{array}$ & Frekuensi & $\begin{array}{c}\text { Persentase } \\
\text { (\%) }\end{array}$ \\
\hline Empati & 35 & $62,5 \%$ \\
Tidak Empati & 21 & $37,5 \%$ \\
Total & 56 & $100 \%$ \\
\hline
\end{tabular}

Sumber: Data Primer (2017)

Berdasarkan tabel 5. di atas, dapat dilihat bahwa sebagian besar $(62,5 \%)$ responden menyatakan perawat memiliki rasa empati terhadap pasien.

f. Gambaran Kepuasan Pasien Terhadap Pelayanan Keperawatan Di Puskesmas Rawat Inap SeKabupaten Kuningan Tahun 2017

Tabel 6.

\begin{tabular}{ccc}
\hline Kepuasan Pasien & Frekuensi & $\begin{array}{c}\text { Persentase } \\
\text { (\%) }\end{array}$ \\
\hline Puas & 29 & $51,8 \%$ \\
Kurang Puas & 27 & $48,2 \%$ \\
Total & 56 & $100 \%$ \\
\hline
\end{tabular}

Sumber: Data Primer (2017)

Berdasarkan tabel 6. di atas dapat dilihat bahwa sebagian besar $(51,8 \%)$ responden merasa puas terhadap pelayanan keperawatan.

2. Analisa Bivariat

$\begin{array}{llr}\text { a. Faktor } & \text { Tangible } & \text { Dengan } \\ \text { Kepuasan } & \text { Pasien Terhadap } \\ \text { Pelayanan } & \text { Keperawatan Di }\end{array}$


Puskesmas Rawat Inap SeKabupaten Kuningan Tahun 2017

Tabel 7.

\begin{tabular}{|c|c|c|c|c|c|c|c|c|}
\hline \multirow{3}{*}{$\begin{array}{c}\text { Tangib/ } \\
\boldsymbol{e}\end{array}$} & \multicolumn{4}{|c|}{ Kepuasan Pasien } & \multirow{2}{*}{\multicolumn{2}{|c|}{ Total }} & \multirow{3}{*}{$p$} & \multirow[b]{2}{*}{ DR } \\
\hline & \multicolumn{2}{|c|}{ Puas } & \multicolumn{2}{|c|}{$\begin{array}{l}\text { Kurang } \\
\text { Puas }\end{array}$} & & & & \\
\hline & $\mathrm{N}$ & $\%$ & n & $\%$ & $n$ & $\%$ & & \\
\hline Baik & 24 & $\begin{array}{l}68, \\
6 \\
\end{array}$ & II & 31,4 & $\begin{array}{l}3 \\
5\end{array}$ & $\begin{array}{l}10 \\
0\end{array}$ & 0,0 & 6,9 \\
\hline $\begin{array}{c}\text { Kurang } \\
\text { Baik }\end{array}$ & 5 & $\begin{array}{l}23, \\
8 \\
\end{array}$ & 16 & 76,2 & 21 & $\begin{array}{l}10 \\
0\end{array}$ & $\begin{array}{l}0 \\
1\end{array}$ & 2 \\
\hline Total & $\begin{array}{l}2 \\
9\end{array}$ & $\begin{array}{l}51, \\
8\end{array}$ & $\begin{array}{l}2 \\
7\end{array}$ & $\begin{array}{l}48, \\
2\end{array}$ & $\begin{array}{l}5 \\
6\end{array}$ & $\begin{array}{l}10 \\
0\end{array}$ & & \\
\hline
\end{tabular}

Sumber: Data Primer (2017)

Berdasarkan tabel 7. di atas, dapat dilihat dari 35 responden yang menyatakan faktor tangible (fasilitas puskesmas dan penampilan perawat) baik, sebagian besar responden $(68,6 \%)$ menyatakan puas.

Berdasarkan hasil Uji Statistik yang dilakukan menggunakan uji ChiSquare didapatkan $p$-value $=0,001<0,05$, sehingga dapat disimpulkan bahwa ada hubungan yang bermakna antara tangible atau bentuk nyata fasilitas yang tersedia dengan kepuasan pasien di Puskesmas Rawat Inap Se-Kabupaten Kuningan.

Nilai Odds Ratio (OR) 6,982 artinya responden yang mengatakan faktor tangible baik mempunyai kecenderungan 6 kali lebih tinggi untuk merasakan puas. Artinya semakin baik fasilitas yang tersedia bagi pasien rawat inap, maka tingkat kepuasan akan semakin tinggi.

b. Faktor Reliability Dengan Kepuasan Pasien Terhadap Pelayanan Keperawatan Di Puskesmas Rawat Inap SeKabupaten Kuningan Tahun 2017
Tabel 8.

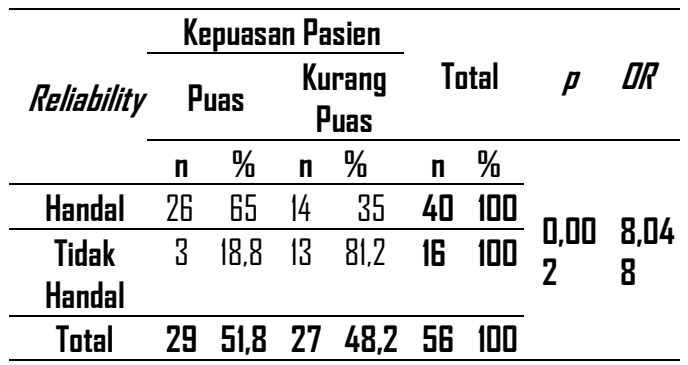

Sumber: Data Primer (2017)

Berdasarkan tabel 8. di atas, dapat dilihat dari 40 responden yang menyatakan dilayani oleh perawat handal, sebagian besar responden $(65 \%)$ merasa puas terhadap kehandalan pelayanan yang diberikan.

Berdasarkan hasil uji statistik dengan menggunakan uji Chi-Square didapatkan p-value $=0,002<0,05$, sehingga dapat disimpulkan bahwa ada hubungan yang bermakna antara Reliability atau kehandalan perawat dengan kepuasan pasien di Puskesmas Rawat Inap SeKabupaten Kuningan.

Nilai Odds Ratio (OR) yaitu sebesar 8,048 artinya responden yang mengatakan pada faktor reliability perawat handal mempunyai kecenderungan 6 kali lebih tinggi untuk merasakan puas Artinya semakin tinggi kehandalan pelayanan perawatan terhadap pasien, maka tingkat kepuasan akan semakin tinggi.

c. Faktor Responsiveness Dengan Kepuasan Pasien Terhadap Pelayanan Keperawatan Di Puskesmas Rawat Inap SeKabupaten Kuningan Tahun 2017

Tabel 9.

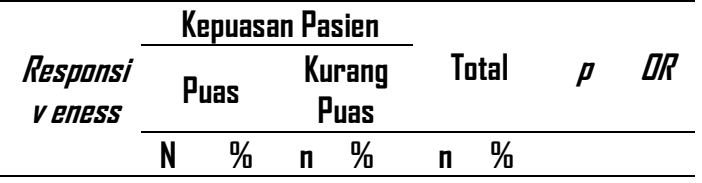




\begin{tabular}{ccccccccc}
\hline Tanggap & 23 & 74, & 8 & 25,8 & 31 & 10 & 0,0 & 9,1 \\
& & 2 & & & & 0 & 0 & 0 \\
Tidak & 6 & 24 & 19 & 76 & 2 & 10 & 0 & 4 \\
Tanggap & 6 & & & & 5 & 0 \\
\hline Total & 2 & 51, & 2 & 48, & 5 & 10 \\
& $\mathbf{9}$ & $\mathbf{8}$ & $\mathbf{7}$ & $\mathbf{2}$ & $\mathbf{6}$ & $\mathbf{0}$ & & \\
& & &
\end{tabular}

Sumber: Data Primer (2017)

Berdasarkan tabel 9. di atas, dapat dilihat dari 31 responden yang merasa perawat cepat tanggap terhadap keluhan pasien, sebagian besar responden $(74,2 \%)$ merasa puas.

Berdasarkan hasil uji statistik yang dilakukan menggunakan uji Chi-Square didapatkan $\mathrm{p}$-value $=0,000<0,05$, sehingga dapat disimpulkan bahwa ada hubungan yang bermakna antara responsiveness atau ketanggapan perawat dengan kepuasan pasien di Puskesmas Rawat Inap Se-Kabupaten Kuningan.

Nilai Odds Ratio (OR) yaitu sebesar 9,104 artinya responden yang mengatakan pada faktor responsiveness perawat cepat tanggap dalam keluhan pasien mempunyai kecenderungan 6 kali lebih tinggi untuk merasakan puas. Artinya semakin tinggi ketanggapan pelayanan keperawatan yang diberikan terhadap pasien, maka tingkat kepuasan akan semakin tinggi.

d. Faktor Assurance Dengan Kepuasan Pasien Terhadap Pelayanan Keperawatan Di Puskesmas Rawat Inap SeKabupaten Kuningan Tahun 2017
Tabel 10.

\begin{tabular}{|c|c|c|c|c|c|c|c|c|}
\hline \multirow{3}{*}{ 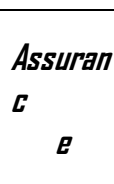 } & \multicolumn{4}{|c|}{ Kepuasan Pasien } & \multirow{2}{*}{\multicolumn{2}{|c|}{ Total }} & \multirow{3}{*}{$p$} & \multirow[b]{2}{*}{ QR } \\
\hline & \multicolumn{2}{|c|}{ Puas } & \multicolumn{2}{|c|}{$\begin{array}{c}\text { Kurang } \\
\text { Puas }\end{array}$} & & & & \\
\hline & $n$ & $\%$ & n & $\%$ & $n$ & $\%$ & & \\
\hline $\begin{array}{l}\text { Terjami } \\
\text { n }\end{array}$ & 21 & $\begin{array}{l}65, \\
6\end{array}$ & II & 34.4 & $\begin{array}{l}3 \\
2\end{array}$ & $\begin{array}{l}10 \\
0\end{array}$ & & \\
\hline $\begin{array}{c}\text { Tidak } \\
\text { Terjami } \\
\mathbf{n}\end{array}$ & 8 & $\begin{array}{l}33, \\
3\end{array}$ & I6 & 66,7 & $\begin{array}{l}2 \\
4\end{array}$ & $\begin{array}{l}10 \\
0\end{array}$ & $\begin{array}{l}0,0 \\
1 \\
6\end{array}$ & $\begin{array}{l}3,8 \\
1 \\
8\end{array}$ \\
\hline Total & $\begin{array}{l}2 \\
9\end{array}$ & $\begin{array}{l}51, \\
8\end{array}$ & $\begin{array}{l}2 \\
7\end{array}$ & $\begin{array}{l}48, \\
2\end{array}$ & $\begin{array}{l}5 \\
6\end{array}$ & $\begin{array}{l}10 \\
0\end{array}$ & & \\
\hline
\end{tabular}

Sumber: Data Primer (2017)

Berdasarkan tabel 10. di atas, dapat dilihat dari 32 responden yang merasa aman dan nyaman terhadap pelayanan yang diberikan perawat, sebagian besar responden $(65,6 \%)$ merasa puas.

Berdasarkan hasil uji statistik yang dilakukan menggunakan uji Chi-Square didapatkan $\mathrm{p}$-value $=0,016<0,05$, sehingga dapat disimpulkan bahwa ada hubungan yang bermakna antara assurance (terjamin/kepastian) dengan kepuasan pasien di Puskesmas Rawat Inap Se-Kabupaten Kuningan.

Nilai Odds Ratio (OR) yaitu sebesar 3,818 artinya responden yang mengatakan pada faktor assurance perawat menjamin informasi dan memberikan rasa aman mempunyai kecenderungan 6 kali lebih tinggi untuk merasakan puas. Artinya semakin tinggi pemberian rasa aman dan nyaman pelayanan diberikan perawat terhadap pasien, maka tingkat kepuasan akan semakin tinggi.

$$
\begin{array}{llr}
\text { e. Faktor } & \text { Empathy } & \text { Dengan } \\
\text { Kepuasan } & \text { Pasien Terhadap } \\
\text { Pelayanan } & \text { Keperawatan Di } \\
\text { Puskesmas Rawat Inap Se- } & \text { Se } \\
\text { Kabupaten Kuningan Tahun } 2017
\end{array}
$$

Tabel 11.

\begin{tabular}{lllll}
\hline Empathy & Kepuasan Pasien & Total & $\boldsymbol{p}$ & QR \\
\hline
\end{tabular}




\begin{tabular}{|c|c|c|c|c|c|c|c|c|}
\hline & \multicolumn{2}{|c|}{ Puas } & \multicolumn{2}{|c|}{$\begin{array}{c}\text { Kurang } \\
\text { Puas }\end{array}$} & \multirow[b]{2}{*}{ n } & \multirow[b]{2}{*}{$\%$} & \multirow[b]{4}{*}{$\begin{array}{l}0,00 \\
0\end{array}$} & \multirow[b]{4}{*}{$\begin{array}{l}10,6 \\
25\end{array}$} \\
\hline & n & $\%$ & $n$ & $\%$ & & & & \\
\hline Empati & 25 & 71,4 & 10 & 28,6 & 35 & 100 & & \\
\hline $\begin{array}{c}\text { Tidak } \\
\text { Empati }\end{array}$ & 4 & 19 & 17 & ا8ا & 21 & 100 & & \\
\hline Total & 29 & 51,8 & 27 & 48,2 & 56 & 100 & & \\
\hline
\end{tabular}

Sumber: Data Primer (2017)

Berdasarkan tabel 5.11 di atas, dapat dilihat dari 35 responden yang menyatakan perawat di puskesmas memiliki empati terhadap pasien, sebagian besar responden $(71,4 \%)$ merasa puas.

Berdasarkan hasil uji statistik yang dilakukan menggunakan uji Chi-Square didapatkan $\mathrm{p}$-value $=0,000<0,05$, sehingga dapat disimpulkan bahwa ada hubungan yang bermakna antara empathy atau kepedulian dengan kepuasan pasien di Puskesmas Rawat Inap Se-Kabupaten Kuningan.

Nilai Odds Ratio (OR) yaitu sebesar 10,625 artinya responden yang mengatakan pada faktor empathy perawat memiliki rasa empati terhadap pasien mempunyai kecenderungan 6 kali lebih tinggi untuk merasakan puas. Artinya semakin tinggi rasa kepedulian perawat terhadap pasien, maka tingkat kepuasan akan semakin tinggi.

\section{SIMPULAN DAN SARAN}

1. Gambaran faktor tangible terhadap pelayanan keperawatan di Puskesmas Rawat Inap Se-Kabupaten Kuningan, sebagian besar mengatakan baik $(62,5 \%)$.

2. Gambaran faktor reliability terhadap pelayanan keperawatan di Puskesmas Rawat Inap Se-Kabupaten Kuningan, sebagian besar mengatakan, dilayani oleh perawat yang handal $(71,4 \%)$.

3. Gambaran faktor responsiveness terhadap pelayanan keperawatan di
Puskesmas Rawat Inap Se-Kabupaten Kuningan, sebagian besar mengatakan, perawat cepat tanggap $(55,4 \%)$.

4. Gambaran faktor assurance terhadap pelayanan keperawatan di Puskesmas Rawat Inap Se-Kabupaten Kuningan, sebagian besar mengatakan, merasa aman dan nyaman terhadap pelayanan yang diberikan perawat $(57,1 \%)$.

5. Gambaran faktor emapthy terhadap pelayanan keperawatan di Puskesmas Rawat Inap Se-Kabupaten Kuningan, sebagian besar mengatakan, perawat memiliki empati terhadap pasien $(62,5 \%)$.

6. Gambaran kepuasan pasien terhadap pelayanan keperawatan di Puskesmas Rawat Inap Se-Kabupaten Kuningan, sebagian besar mengatakan puas terhadap pelayanan keperawatan $(51,8 \%)$.

7. Terdapat hubungan yang signifikan antara faktor tangible dengan kepuasan pasien terhadap pelayanan keperawatan di Puskesmas Rawat Inap Se-Kabupaten Kuningan dengan $p$-value $=0,001$.

8. Terdapat hubungan yang signifikan antara faktor reliability dengan kepuasan pasien terhadap pelayanan keperawatan di Puskesmas Rawat Inap Se-Kabupaten Kuningan dengan pvalue $=0,002$.

9. Terdapat hubungan yang signifikan antara faktor responsiveness dengan kepuasan pasien terhadap pelayanan keperawatan di Puskesmas Rawat Inap Se-Kabupaten Kuningan dengan pvalue $=0,000$.

10. Terdapat hubungan yang signifikan antara faktor assurance dengan kepuasan pasien terhadap pelayanan keperawatan di Puskesmas Rawat Inap Se-Kabupaten Kuningan dengan pvalue $=0,016$.

11. Terdapat hubungan yang signifikan antara faktor empathy dengan 
kepuasan pasien terhadap pelayanan keperawatan di Puskesmas Rawat Inap Se-Kabupaten Kuningan dengan $p$-value $=0,000$.

\section{Bagi Pasien}

Hasil penelitian ini meningkatkan pengetahuan pasien rawat inap terkait pelayanan keperawatan yang diberikan oleh puskesmas yang berada di daerah tertentu, sehingga pasien dapat berobat ke puskesmas tersebut dengan nyaman.

2. Bagi Puskesmas

Hasil penelitian ini disarankan menjadi bahan masukan kepada pihak Puskesmas dalam pengambilan kebijakan pelayanan keperawatan terkait kualitas kebersihan toilet, kehandalan perawat, ketanggapan perawat dalam memberikan informasi terkait hasil laboratorium dan perawat agar lebih empati kepada pasien tanpa harus diminta.

3. Bagi Stikes Kuningan

Hendaknya pihak institusi Stikes Kuningan memperbanyak buku mengenai manajemen keperawatan dan jurnal terbaru untuk mempermudah mahasiswa yang sedang penelitian sebagai bahan referensi.

4. Bagi Peneliti Selanjutnya Diharapkan dapat melakukan penelitian lebih lanjut tentang tingkat kepuasan pasien dalam upaya peningkatan mutu pelayanan kesehatan dengan motodologi dan rancangan penelitian yang berbeda, cakupan responden yang lebih luas dengan kasus yang berbeda.

\section{DAFTAR PUSTAKA}

Ayuningtyas, K.R., Mustayah dan Nataliswati Tri. (2015). Tingkat Kepuasan Pasien Pada Pelayanan Keperawatan Di Rumah Sakit. Junal. Pendidikan Kesehatan, Volume 4. No. 2: pp 83-90

Bustami. (2011). Penjaminan Mutu Pelayanan Kesehatan Dan Akseptabilitasnya. Jakarta: Erlangga

Efendi, Fery dan Makhfudi. (2009). Keperawatan Kesehatan Komunitas: Teori dan Praktek dalam Keperawatan. Jakarta: Salemba Medika

Kemenkes. (2015). Profil Kesehatan Indonesia. Profi Kemenkes. Diperoleh dari www. depkes.go.id/.../profil kesehatanindonesia/profilkesehatan Indonesia2015.pdf.Tanggal 30 Januari 2017

Mumu, L.J, Kandou, G.D dan Doda, D.V. (2015). Analisis Faktor-Faktor Yang Berhubungan Dengan Kepuasan Pasien Di Poliklinik Penyakit Dalam RSUP Prof. R. D Kandou Manado. Jurnal. Program Pascasarjana. Fakultas Ilmu Kesehatan Masyarakat. Universitas Sam Ratulangi Manado. Volume 5. No. 4

Nursalam. (2011). Konsep dan Penerapan Metodologi Penelitian Ilmu Keperawatan. Jakarta: Salemba Medika

Nursalam. (2012). Manajemen Keperawatan Aplikasi dalam Praktik Keperawatan Profesional Edisi 3. Jakarta: Salemba Medika 
Oroh, M. E., Rompas, E dan Pondag, L. (2014). Faktor-Faktor Yang Berhubungan Dengan Tingkat Kepuasan Pasien Rawat Inap Terhadap Pelayanan Keperawatan Di Ruang Interna RSUD Noongan. Jurnal. Program Studi ilmu keperawatan. Fakultas Kedokteran. Universitas Sam Ratulangi Manado. Volume 2. No. 2

Putri Aulia dan Putra Hedu Adita. (2014).

Faktor-Faktor Yang

Berhubungan Dengan Kepuasan

Pasien Dalam Pelayanan Keperawatan Di Ruang Rawat Interne Pria Dan Wanita RSUD Dr. Achmad Mochtar Bukit Tinggi. Jurnal. Program Studi IlmuKeperawatan. Stikes Yarsi Sumber Bukit Tinggi.

Rusmaningsih Esri dan Elsera Chori. (2017). Analisis kepuasan pelayanan keperawatan pada pasien peserta jaminan kesehatan nasional (JKN) di RSUD pandan arang boyolali. Jurnal. Program DIII Keperawatan. Stikes Muhammadiyah Klaten

Tjiptono, F. (2014). Pemasaran Jasa Prinsip, Penerapan, dan Penelitian. Yogyakarta: ANDI

Wulandari Nofianti. (2015). Hubungan Layanan Keperawatan Dengan Tingkat Kepuasan Pasien Rawat Inap di Rumah Sakit Umum Daerah (RSUD) Ungaran Kabupaten Semarang. Skripsi. Program Pascasarjana. Fakultas Ilmu Keolahraga Universitas Nergi Semarang.
Zaidin, Ali. (2012). Dasar-Dasar Keperawatan Profesional. Jakarta: Widya Medika . (2015). Profil Dinas Kesehatan Kabupaten Kuningan. Diakses pada tanggal 02 Februari 2017 